\title{
The effect of surface modification of mesoporous carbons on Auramine-O dye removal from water
}

\author{
Joanna Goscianska $^{1} \cdot$ Michal Marciniak $^{1} \cdot$ Robert Pietrzak $^{1}$
}

Received: 12 October 2015/Revised: 11 November 2015/Accepted: 13 November 2015/Published online: 23 November 2015

(C) The Author(s) 2015. This article is published with open access at Springerlink.com

\begin{abstract}
Mesoporous carbon of regular structure was subjected to oxidation by ammonium persulfate at 30,60 or $100{ }^{\circ} \mathrm{C}$. The mesostructure and pore evolution were characterised by XRD, TEM, and $\mathrm{N}_{2}$ sorption techniques. The functional groups present on the surface of the carbon materials were identified by FTIR and thermogravimetric studies. It was established that the micropores and small mesopores could be blocked by the surface oxides attached under mild oxidation. High densities of surface oxygen complexes, especially carboxylic groups, were generated on the surface of mesoporous carbons. All materials obtained were tested for the removal of Auramine-O from aqueous solution. Adsorption experiments were carried out as batch studies at different contact time, $\mathrm{pH}$ and initial dye concentration. Removal of this cationic dye in basic solutions was more effective than in acidic solutions. The highest sorption capacity towards Auramine-O was obtained for the carbon sample oxidised by ammonium persulfate solution at $100{ }^{\circ} \mathrm{C}$. Fitting equilibrium data to Langmuir and Freundlich isotherms showed that Langmuir model was more suitable to describe the Auramine-O adsorption. The changes in standard enthalpy $\left(\Delta \mathrm{H}^{0}\right)$, standard entropy $\left(\Delta S^{0}\right)$ and Gibbs free energy $\left(\Delta G^{0}\right)$ were analysed. Thermodynamic study showed that the adsorption of Auramine-O was a spontaneous and exothermic process.
\end{abstract}

Joanna Goscianska

asiagosc@amu.edu.pl

$\triangle$ Robert Pietrzak

pietrob@amu.edu.pl

1 Faculty of Chemistry, Adam Mickiewicz University in Poznań, Umultowska 89b, 61-614 Poznań, Poland
Keywords Adsorption of dye $\cdot$ Basic yellow $2 \cdot$ Ordered mesoporous carbons - Wet oxidation - Modification with ammonium persulfate . Thermodynamic study

\section{Introduction}

Since their discovery, mesoporous carbons have been the object of great interest because of their exceptional properties. They show well-developed surface area, well-defined pore size, large pore volume and high thermal stability (Ryoo et al. 1999, 2001; Jun et al. 2000). Therefore they have been widely used as supports for catalysts (Kim et al. 2015), sensors (Feng et al. 2007; Zhou et al. 2007), elements of fuel cells (Lin et al. 2009), in construction of bio-reactors (Hartmann 2005) and in adsorptive treatment of water and air (Goscianska et al. 2014, 2015a, b; Tian et al. 2011). The neutral and hydrophobic character of the ordered carbons prompted taking up attempts at modification of their surfaces by introduction of diverse functional groups.

Oxidation of carbon materials is one of the most popular methods for increasing the number of surface oxygen functional groups (Bazuła et al. 2008; Wu et al. 2010; Tanaka et al. 2015). The oxidising agents used for this purpose can be divided into two groups. The first group includes gas oxidisers such as oxygen, ozone, carbon dioxide and steam. The process of oxidation with their use is performed at temperatures above $700{ }^{\circ} \mathrm{C}$, and the surface oxygen complexes formed are unstable and decompose at high temperature (Wu et al. 2010). The second group of oxidisers are the solutions containing oxidising substances such as e.g. nitric acid, perchloric acid, ammonium persulfate and hydrogen peroxide. Wet oxidation is usually performed at temperatures $20-150{ }^{\circ} \mathrm{C}$ (Lazaro et al. 2007; 
Wu et al. 2010; Deng et al. 2010; Moreno-Tovar et al. 2014; Tanaka et al. 2015; Barczak et al. 2015). Often nitric acid is used since its oxidizing properties can be controlled by adjusting the concentration and temperature (Lazaro et al. 2007; Bazuła et al. 2008; Wu et al. 2010; Deng et al. 2010). However, its use can lead to a considerable decrease in the carbon surface area and even to destruction of carbons mesoporous structure already at about $80{ }^{\circ} \mathrm{C}$. Hydrogen peroxide can be used to generate surface oxides, but it is very toxic and can also damage the mesostructure of carbon materials (Wu et al. 2010). In contrast, acidic ammonium persulfate solution is a gentle and less-toxic oxidant with a good capability of generating surface oxides and without causing obvious damage to the porous structure (Wu et al. 2010; Barczak et al. 2015).

Depending on the type of the oxidising agent used and the conditions of the modification (e.g. temperature, time), not only an increase in the number of surface oxygen functional groups but also different contributions of the types of these groups can be achieved (Wu et al. 2010; Tanaka et al. 2015). The surface oxygen groups can be acidic, e.g. carboxylic, phenolic, carbonyl of quinone type or lactone, or basic, e.g. chromenic, pironic. The oxygen functional groups present on the surface of carbon adsorbents are analogous to the typical functional groups met in organic compounds. As a result of the process of oxidation, the sorption capacities of mesoporous carbons (characterised with highly hydrophobic properties) towards esters, amines, functional dyes and heavy metal ions significantly improve (Wu et al. 2010; Barczak et al. 2015).

The main aim of this study was a systematic characterisation of a series of mesoporous carbons of regular structure, subjected to oxidation with a solution of ammonium persulfate in different conditions. Changes taking place on the surface of the mesoporous carbon samples upon their oxidation were examined by FTIR spectroscopy and thermogravimetric analysis. Moreover, the functionalised mesoporous carbons were used as a highly efficient adsorbents in removal of Auramine-O (AO), basic yellow dye (Fig. 1), from aqueous solutions. International Agency for Research on Cancer provided more evidence of carcinogenicity ability of AO among<smiles>CN(C)c1ccc(C(=[NH2+])c2ccc(N(C)C)cc2)cc1</smiles>

Fig. 1 Structure of Auramine-O chemicals related to its bio-transformation to reactive species in target organs of both rats and humans (Martelli et al. 1998; Asfaram et al. 2015). Therefore, effective methods for its removal have been searched for in many laboratories in the world.

\section{Experimental}

\subsection{Synthesis of mesoporous carbon}

Mesoporous carbon of regular structure was obtained by the hard-template method, using KIT-6 silica material as a template and sucrose as a carbon precursor (Goscianska et al. 2014, 2015a, b). The silica was subjected twice to impregnation with a sucrose solution; $1 \mathrm{~g}$ of KIT- 6 was added to a solution obtained by dissolving $1.4 \mathrm{~g}$ of sucrose (Aldrich) and $0.14 \mathrm{~g}$ of $\mathrm{H}_{2} \mathrm{SO}_{4}$ (Chempur, $98 \%$ ) in $6 \mathrm{ml}$ of distilled water. The mixture was heated in a furnace for $6 \mathrm{~h}$ at $100{ }^{\circ} \mathrm{C}$, and then for the next $6 \mathrm{~h}$ at $160{ }^{\circ} \mathrm{C}$. The silica-carbon composite containing partially polymerised and carbonised sucrose, was subjected to subsequent impregnation with a solution containing $0.8 \mathrm{~g}$ of sucrose, $0.09 \mathrm{ml}$ of sulphuric acid and $6 \mathrm{ml}$ of distilled water. The material was heated for $6 \mathrm{~h}$ in a furnace at $100{ }^{\circ} \mathrm{C}$ and then for $6 \mathrm{~h}$ at $160{ }^{\circ} \mathrm{C}$. Subsequently the material was subjected to carbonisation at $900{ }^{\circ} \mathrm{C}(8 \mathrm{~h})$ in an argon atmosphere at the heating rate $5{ }^{\circ} \mathrm{C} /$ min. Finally, the mesoporous carbon denoted as $\mathrm{C}_{\mathrm{KIT}-6}$ was obtained by removing the silica matrix with the use of a 5 wt $\%$ hydrofluoric acid at room temperature followed by filtration, washing, and drying at $100{ }^{\circ} \mathrm{C}$ for $4 \mathrm{~h}$.

\subsection{Surface functionalisation}

Mesoporous carbon $\mathrm{C}_{\mathrm{KIT}-6}$ was treated with a mild oxidant of $1 \mathrm{M}$ ammonium persulfate solution-APS (prepared in $\left.2 \mathrm{M} \mathrm{H}_{2} \mathrm{SO}_{4}\right)$. Various temperatures $\left(30,60,100{ }^{\circ} \mathrm{C}\right)$ were adopted to achieve different levels of surface modification.

For a typical treatment, $0.5 \mathrm{~g}$ of mesoporous carbon and $30 \mathrm{ml}$ of freshly prepared $1 \mathrm{M}$ acidic APS solution were added into a round flask. The mixture was stirred and refluxed at 30,60 or $100{ }^{\circ} \mathrm{C}$ for $6 \mathrm{~h}$. In the next step, the solid was filtered, washed with water as well as ethanol and dried at $60{ }^{\circ} \mathrm{C}$ for $12 \mathrm{~h}$.

The functionalised samples were denoted as $\mathrm{C}_{\mathrm{KIT}-6^{-}}$ APS- $x$, where $\mathrm{x}$ stands for the treatment temperature $\left({ }^{\circ} \mathrm{C}\right)$.

\subsection{Sample characterisation}

\subsubsection{Powder X-ray diffraction (XRD)}

The materials prepared were characterised by X-ray diffraction (XRD) using a D8 Advance diffractometer 
(Bruker) $\left(\mathrm{CuK}_{\alpha}\right.$ radiation, $\left.\lambda=0.154 \mathrm{~nm}\right)$, with a step size $0.02^{\circ}$ in the small-angle range.

\subsubsection{Transmission electron microscopy (TEM)}

For TEM measurements, powdered samples were deposited on a grid with a perforated carbon film and transferred to a JEOL 2000 electron microscope operating at $80 \mathrm{kV}$.

\subsubsection{Nitrogen sorption}

Characterisation of the pore structure of samples obtained was performed on the basis of low-temperature nitrogen adsorption-desorption isotherms measured on a sorptometer Quantachrome Autosorb iQ. Prior to adsorption measurements, the samples were degassed in vacuum at $300{ }^{\circ} \mathrm{C}$ for $2 \mathrm{~h}$. Surface area and pore size distribution were calculated by BET and BJH methods, respectively. Total pore volume and average pore diameter were determined as well. Micropore volume and area were calculated using the t-plot method.

\subsubsection{Boehm titration}

The contents of oxygen functional groups on the surface of the carbon samples obtained were determined by the Boehm method, which permits determination of the acidbase properties of the materials (Boehm 1994). In order to find out the total content of acidic oxygen groups present on the carbon samples surface, the material was neutralised with a $0.1 \mathrm{M}$ solution of sodium hydroxide. The excess of $\mathrm{NaOH}$ was evaluated by back titration with $0.1 \mathrm{M} \mathrm{HCl}$ solution in the presence of methyl orange as an indicator. To establish the total content of basic oxygen groups on the surface of mesoporous carbon samples, they were neutralised by $0.1 \mathrm{M} \mathrm{HCl}$. The excess of $\mathrm{HCl}$ was determined by back titration with $0.1 \mathrm{M}$ solution of $\mathrm{NaOH}$ in the presence of methyl orange.

\subsubsection{FTIR}

To identify the functional groups present on the surface of carbon materials, they were subjected to FTIR study. The mesoporous carbons were mixed with dried potassium bromide, at the rate of $1 \mathrm{mg}$ of carbon per $200 \mathrm{mg} \mathrm{KBr}$. Fourier transform infrared spectra in the range $400-4000 \mathrm{~cm}^{-1}$ were collected on an FT-IR Bruker spectrometer IFS $66 \mathrm{v} / \mathrm{S}$.

\subsubsection{Thermal analysis}

Thermogravimetric analysis was performed on an SETSYS 12 made by Setaram.
The samples $(10 \mathrm{mg})$ were heated at the rate $10{ }^{\circ} \mathrm{C} / \mathrm{min}$, in nitrogen atmosphere. The analysis lasted for $100 \mathrm{~min}$ and the temperature during the decomposition was varied from 20 to $1000{ }^{\circ} \mathrm{C}$.

\subsection{Auramine-O adsorption process}

For determination of adsorption capacity of mesoporous carbon materials towards $\mathrm{AO}$, a portion of $20 \mathrm{mg}$ of the adsorbent was flooded with $50 \mathrm{ml}$ of the dye solution of a given concentration $(25-500 \mathrm{mg} / \mathrm{l})$. Each mixture was stirred until the equilibrium was reached. After adsorption, the concentration of dye solution was determined using a UV-Vis spectrophotometer. The maximum absorbance wavelength for $\mathrm{AO}$ is $431 \mathrm{~nm}$. The equilibrium adsorption capacities $\left(\mathrm{q}_{\mathrm{e}}\right)$ were determined according to the following formula:

$q_{e}=\frac{\left(C_{0}-C_{e}\right) \cdot V}{m}$

wherein $\mathrm{C}_{0}$ is the initial concentration of $\mathrm{AO}, \mathrm{C}_{\mathrm{e}}$ is the residual concentration of $\mathrm{AO}, \mathrm{V}$ is the volume of the solution, $\mathrm{m}$ is the mass of the adsorbent.

The effect of $\mathrm{pH}$ on dye removal was studied over a $\mathrm{pH}$ range of 2-12. The initial $\mathrm{pH}$ of the dye solution was adjusted by the addition of $1 \mathrm{M}$ solution of $\mathrm{HCl}$ or $\mathrm{NaOH}$. The sorption studies were also carried out at $25,35,45{ }^{\circ} \mathrm{C}$ to determine the effect of temperature, in order to evaluate the thermodynamical parameters.

\section{Results and discussion}

\subsection{Characterisation of mesoporous adsorbents}

The information on structural properties of the materials synthesised was obtained by X-ray diffraction (XRD) and transmission electron microscopy (TEM) methods. The XRD pattern of $\mathrm{C}_{\mathrm{KIT}-6}$ in the small-angle range shows an intensive peak at $2 \Theta \approx 1^{\circ}$ corresponding to the (211) plane and reflexes in the range $2 \Theta \approx 1.8-2.3^{\circ}$, evidencing the highly ordered regular structure (Fig. 2). The oxidation of this sample with $1 \mathrm{M}$ acidic solution of APS at 30,60, or $100{ }^{\circ} \mathrm{C}$ for $6 \mathrm{~h}$ led to decreased intensity of all peaks.

The TEM images reveal the mesostructural stability of carbon material after wet oxidation by the acidic APS solution (Fig. 3). Generally, the regular structure can be clearly observed regardless of the treatment conditions. After modification at a low temperatures $\left(30,60^{\circ} \mathrm{C}\right)$ for $6 \mathrm{~h}$, the carbon samples still exhibit a high-quality mesostructure. After treatment at $100{ }^{\circ} \mathrm{C}$ the mesostructural regularity is still preserved, however small structural changes are observed. 


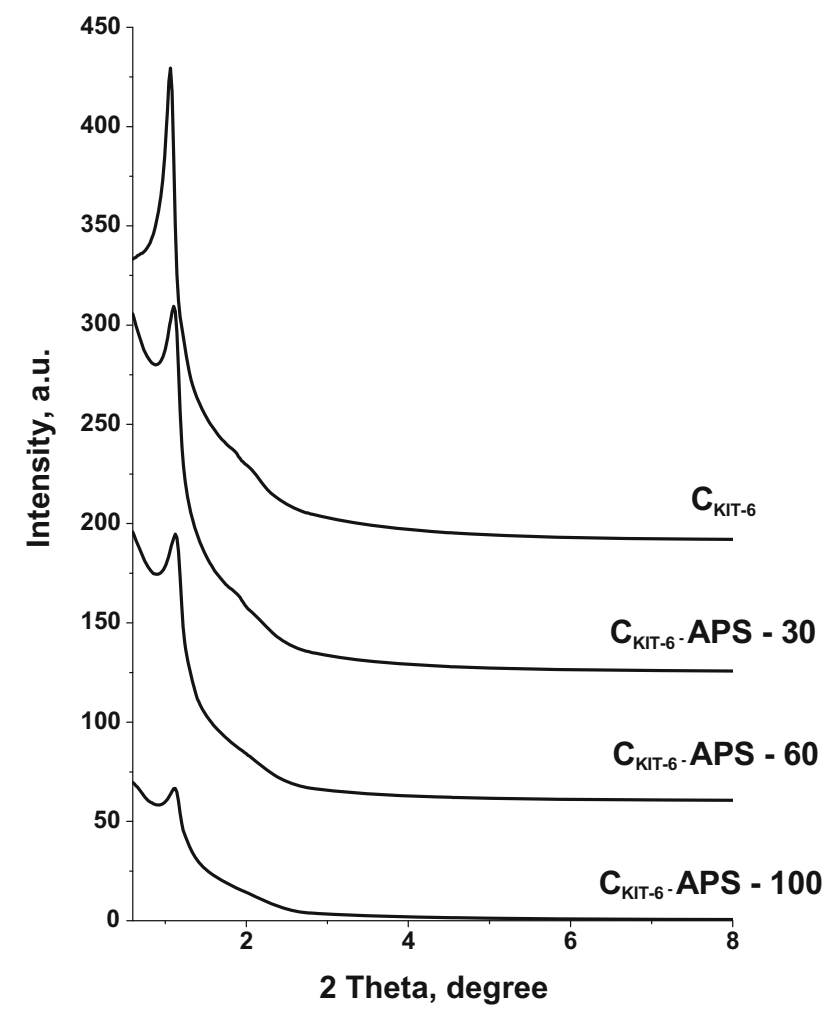

Fig. 2 Small-angle X-ray diffraction patterns of ordered mesoporous carbons

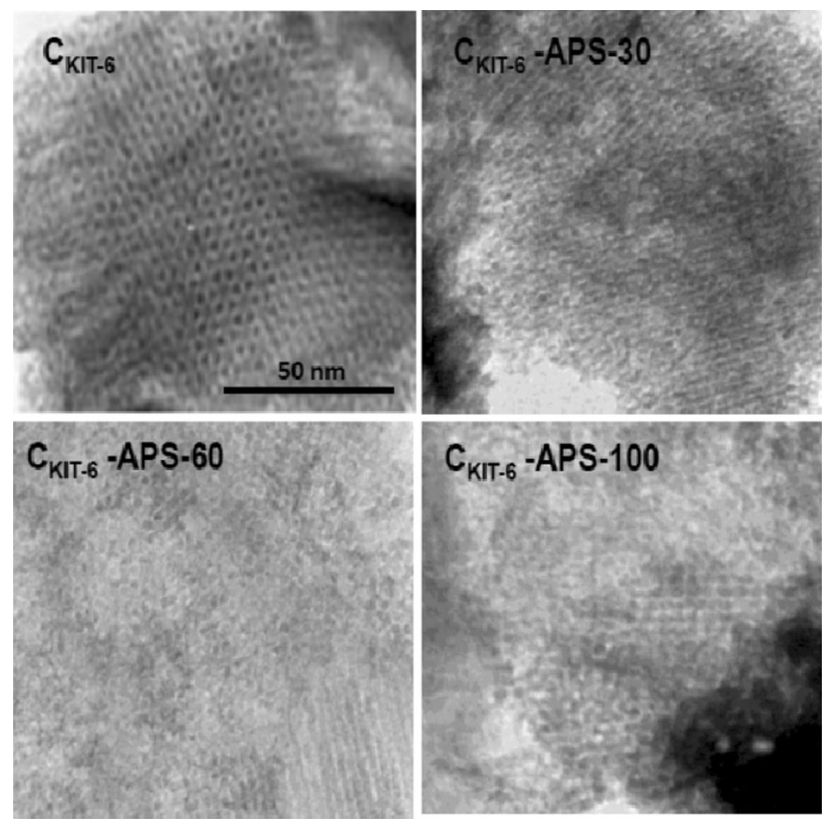

Fig. 3 TEM images of $\mathrm{C}_{\mathrm{KIT}-6}, \mathrm{C}_{\mathrm{KIT}-6}$-APS-30, $\mathrm{C}_{\mathrm{KIT}-6}$-APS-60, $\mathrm{C}_{\mathrm{KIT}-}$ 6 -APS-100

The parameters characterising textural properties of the samples studied are collected in Table 1. Pure carbon $\mathrm{C}_{\mathrm{KIT}-6}$ has the best developed surface area of $799 \mathrm{~m}^{2} / \mathrm{g}$ and large pore volume of $1.15 \mathrm{ml} / \mathrm{g}$. Besides mesopores, this sample also has micropores localised in the mesopores walls. The process of oxidation with ammonium persulfate has a significant effect on the textural parameters. The modified samples were found to have smaller surface area and pore volume than those of pure $\mathrm{C}_{\mathrm{KIT}-6}$. It can be concluded that during oxidation process a part of micropores and/or small mesopores are blocked. The surface oxygen functional groups most probably take positions at the entrance to micropores, which causes a reduction in their area and volume.

As a result of $\mathrm{C}_{\mathrm{KIT}-6}$ carbon oxidation with ammonium persulfate many different oxygen functional groups, analogous to those present in typical organic compounds, are formed. The amounts of acidic and basic oxygen groups formed on the surface of $\mathrm{C}_{\mathrm{KIT}-6}$ were determined by the Boehm method and the results are given in Table 2. It was indicated that oxidation of $\mathrm{C}_{\mathrm{KIT}-6}$ with ammonium persulfate caused an increase in the content of surface oxygen groups of acidic nature and their content depends first of all on the conditions of the oxidation process. The samples C $_{\text {KIT-6-APS-30, }}$ C $_{\text {KIT-6- }}$-APS-60, C $_{\text {KIT-6- }}$-APS-100 were found to contain $3.37,4.10$ and $4.21 \mathrm{mmol} / \mathrm{g}$ of the acidic functional groups. With increasing temperature of oxidation, the content of acidic functional groups on the surface of carbons increased. The samples subjected to oxidation with ammonium persulfate at 30 and $60{ }^{\circ} \mathrm{C}\left(\mathrm{C}_{\mathrm{KIT}-6}\right.$-APS$30, \mathrm{C}_{\mathrm{KIT}-6}$-APS-60) were found not to contain surface oxygen groups of basic nature.

The functional oxygen groups present on the surface of the mesoporous carbon samples after the process of oxidation were identified on the basis of the infrared spectra (Fig. 4). In the spectra of pristine material $\mathrm{C}_{\mathrm{KIT}-6}$, the broad band at a wavenumber of $3650-3350 \mathrm{~cm}^{-1}$ is generated by the stretching vibration of hydroxyl groups (Ciesielczyk et al. 2015a). The weak bands at $\sim 1645$ and $1549 \mathrm{~cm}^{-1}$ could probably be assigned to a small amount of carbonyl groups conjugated in the graphene layer such as the quinone structure $\mathrm{C}=\mathrm{O}$ and a small amount of $\mathrm{C}=\mathrm{C}$, as well as $\mathrm{C}-\mathrm{H}$ groups in the surface aromatic structure (Jia and Thomas 2000; $\mathrm{Wu}$ et al. 2010). The presence of $\mathrm{C}-\mathrm{H}$ groups was also indicated by the bands at around 1441 and $1380 \mathrm{~cm}^{-1}$ (Álvarez et al. 2015). The FTIR spectra of the surfaces of oxidised samples evidently prove that the oxidation with APS leads to generation of oxygen functional groups. The spectra recorded after the modification reveal a band at $\sim 1734 \mathrm{~cm}^{-1}$, which in literature is assigned to the vibration of $\mathrm{C}=\mathrm{O}$ bond in the carboxyl group. The bands at $\sim 1215$ and $1120 \mathrm{~cm}^{-1}$ can be assigned to the $\mathrm{C}-\mathrm{O}$ bonds in ester, phenolic, etheric and carboxylic groups (Tanaka et al. 2015). FTIR spectra of the samples oxidised in different oxidation conditions show similar bands assigned to oxygen-containing groups but their intensity 
Table 1 Textural parameters of mesoporous carbons functionalised with APS

\begin{tabular}{llllll}
\hline Sample & $\begin{array}{l}\text { Total surface } \\
\text { area }\left(\mathrm{m}^{2} / \mathrm{g}\right)\end{array}$ & $\begin{array}{l}\text { Micropore } \\
\text { area }\left(\mathrm{m}^{2} / \mathrm{g}\right)\end{array}$ & $\begin{array}{l}\text { Total pore } \\
\text { volume }(\mathrm{ml} / \mathrm{g})\end{array}$ & $\begin{array}{l}\text { Micropore } \\
\text { volume }(\mathrm{ml} / \mathrm{g})\end{array}$ & $\begin{array}{l}\text { Average pore } \\
\text { diameter }(\mathrm{nm})\end{array}$ \\
\hline C $_{\text {KIT-6 }}$ & 799 & 322 & 1.15 & 0.34 & 5.78 \\
C $_{\text {KIT-6-APS-30 }}$ & 627 & 306 & 0.91 & 0.26 & 5.83 \\
C $_{\text {KIT-6 }}$ APS-60 & 583 & 252 & 0.79 & 0.22 & 5.90 \\
C $_{\text {KIT-6-APS-100 }}$ & 562 & 239 & 0.76 & 0.20 & 6.03 \\
\hline
\end{tabular}

Table 2 Amount of functional groups on the surface of mesoporous carbons

\begin{tabular}{llll}
\hline Material & Acidic groups $(\mathrm{mmol} / \mathrm{g})$ & Basic groups $(\mathrm{mmol} / \mathrm{g})$ & Total content of surface oxides $(\mathrm{mmol} / \mathrm{g})$ \\
\hline $\mathrm{C}_{\text {KIT-6 }}$ & 1.09 & 0.74 & 1.83 \\
$\mathrm{C}_{\text {KIT-6 }}$-APS-30 & 3.37 & 0.00 & 3.37 \\
$\mathrm{C}_{\text {KIT-6 }}$-APS-60 & 4.10 & 0.00 & 4.10 \\
C $_{\text {KIT-6 }}$ APS-100 & 4.21 & 0.50 & 4.71 \\
\hline
\end{tabular}

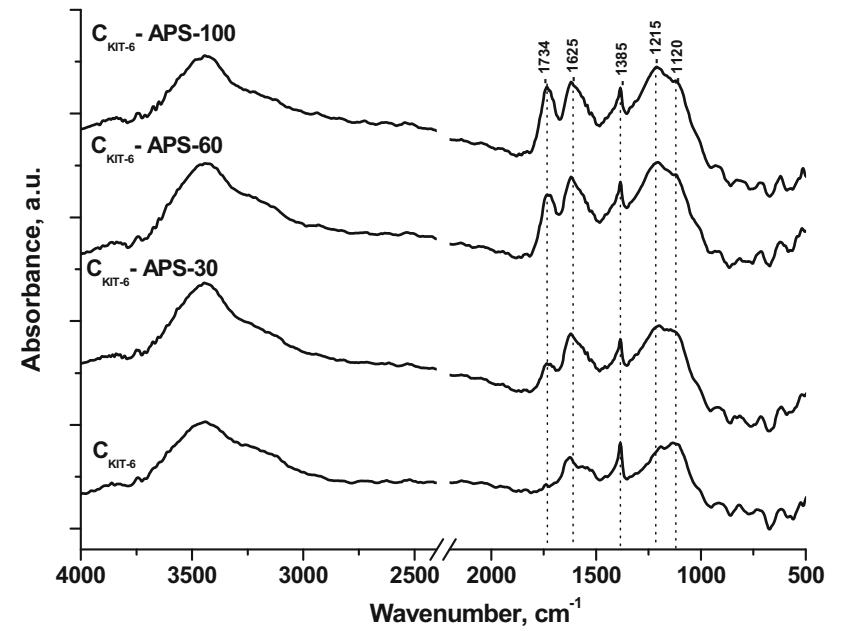

Fig. 4 FTIR spectra of mesoporous carbons

increases with increasing oxidation temperature, indicating that higher temperature is favourable for generation of higher density of functional groups (Fig. 4).

Thermogravimetric measurements of the carbon materials obtained were performed and their results in the form of mass loss plots as a function of temperature are shown in Fig. 5. Upon heating the samples to about $150{ }^{\circ} \mathrm{C}$ a mass loss related to thermal desorption of water was observed. The greater the mass of the water removed the higher the hydrophilicity of the material. As pristine carbon $\mathrm{C}_{\mathrm{KIT}-6}$ was carbonised at $900{ }^{\circ} \mathrm{C}$, its DTG curve showed no peaks in the range $150-1000{ }^{\circ} \mathrm{C}$ (Fig. 5a). The TG curve shows that this sample gives very small weight loss (Fig. 5b). The mass loss recorded in the temperatures $150-800{ }^{\circ} \mathrm{C}$ for the samples $\mathrm{C}_{\mathrm{KIT}-6}$-APS-30, $\mathrm{C}_{\mathrm{KIT}-6}$-APS-60, $\mathrm{C}_{\mathrm{KIT}-6}$-APS-100 oxidised by ammonium persulfate was interpreted as a result of decomposition of the oxygen functional groups present on the surface of these samples. The peak on the DTG curves below $280{ }^{\circ} \mathrm{C}$ is assigned to the decomposition of carboxylic groups. The less pronounced peak appearing in the range $280-400{ }^{\circ} \mathrm{C}$ is assigned to the decomposition of phenolic groups (Otake and Jenkins 1993; Wu et al. 2010). The peaks at higher temperatures $\left(450-650{ }^{\circ} \mathrm{C}\right)$ can be attributed to the decomposition of lactone, quinine and anhydride groups (Wu et al. 2010). It should be noted that with increasing temperature of $\mathrm{C}_{\mathrm{KIT}-6}$ carbon oxidation, the mass losses corresponding to the decompositions of particular functional groups are greater.

\subsection{Adsorption studies}

The effect of the contact time on the adsorption of AO was investigated at room temperature. The results are shown in Fig. 6. Adsorption of this dye is rapid in the first $30 \mathrm{~min}$ and, thereafter, its rate decreased gradually. The amount of $\mathrm{AO}$ adsorbed reached a constant value after $100 \mathrm{~min}$. In the initial stage of the process, a large number of vacant surface sites are available for adsorption of AO. After a lapse of some time, the remaining vacant surface sites are difficult to be occupied due to repulsive forces between the solute molecules on the solid surface and the bulk phase. Besides, the dye molecules are adsorbed into the mesopores that get almost saturated with $\mathrm{AO}$ ions during the initial stage of adsorption. The dye molecules have to traverse farther and deeper into the pores encountering much greater resistance. This results in the slowing down of the adsorption in the later period of the process (Mall et al. 2007; Asfaram et al. 2015).

The $\mathrm{pH}$ value of $\mathrm{AO}$ solutions has little effect on the sorption capacities of the mesoporous carbon samples 

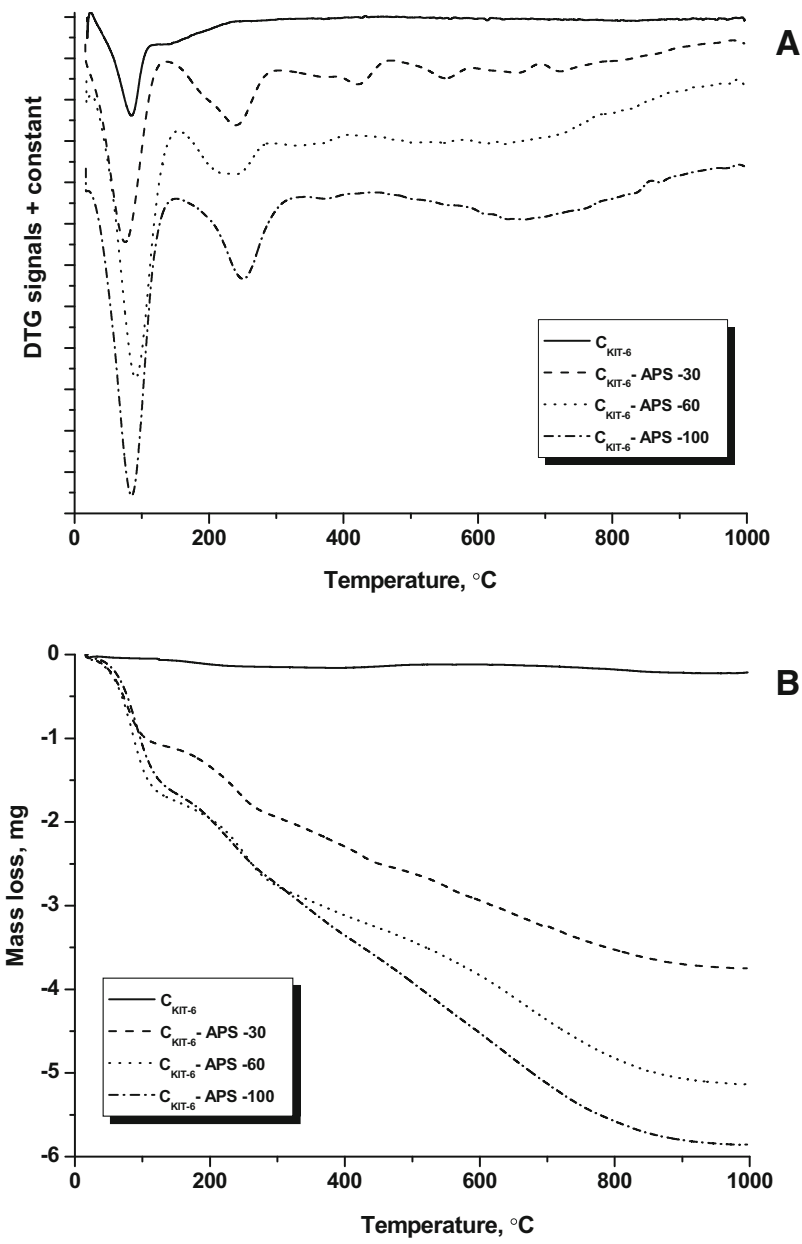

Fig. 5 DTG (a) and TG (b) curves of mesoporous carbons

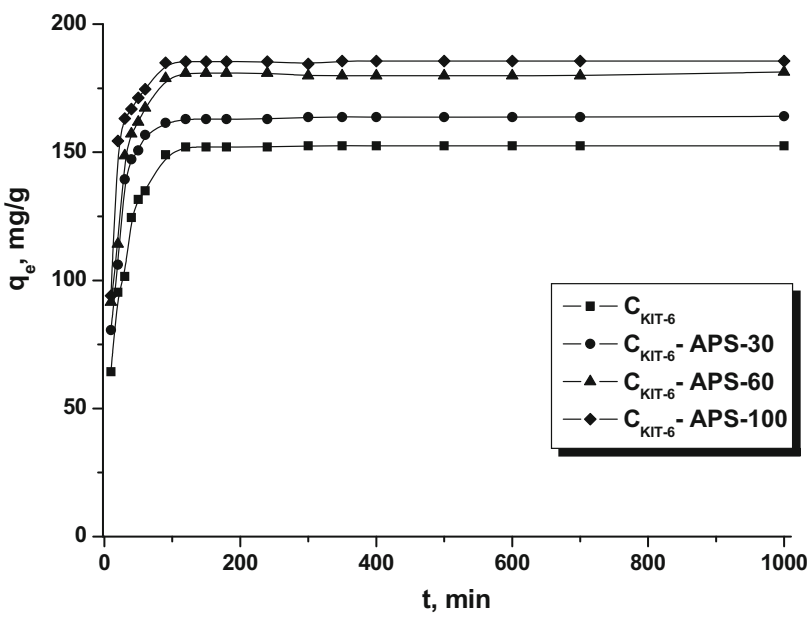

Fig. 6 Amount of Auramine-O adsorbed as a function of contact time (initial solution concentration of dye $-75 \mathrm{mg} / \mathrm{l}$ )

towards this dye. Figure 7 presents the amount of adsorbed $\mathrm{AO}$ as a function of $\mathrm{pH}$ of the dye solutions used. The sorption capacities of all samples slightly increase with

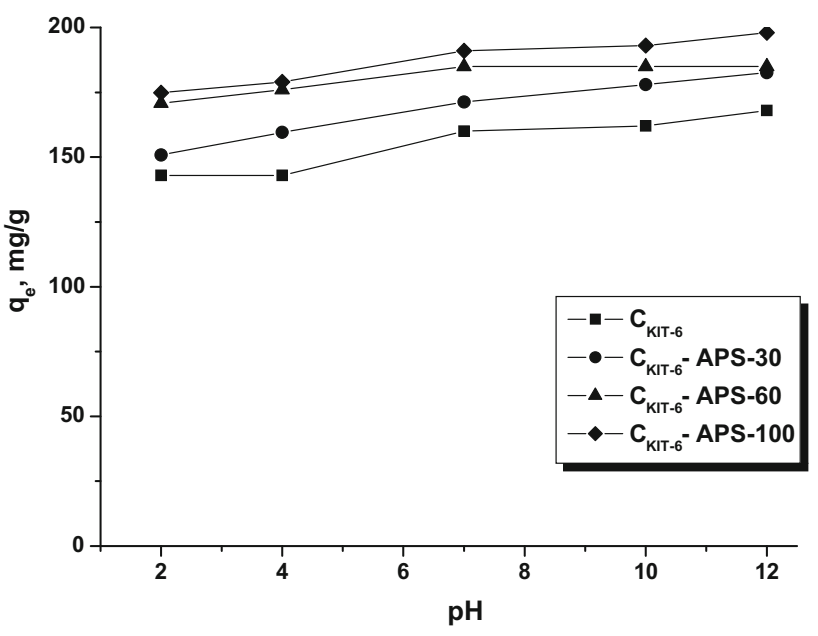

Fig. 7 Effect of $\mathrm{pH}$ on the removal of Auramine-O dye by mesoporous carbons (initial solution concentration of dye $-75 \mathrm{mg} / \mathrm{l}$ )

increasing $\mathrm{pH}$ value. At higher $\mathrm{pH}$, the association of dye cations with more negative charge sites of $\mathrm{C}_{\mathrm{KIT}-6}$-APS-30, $\mathrm{C}_{\mathrm{KIT}-6}$-APS-60, $\mathrm{C}_{\mathrm{KIT}-6}$-APS-100 could easily take place, thereby increasing dye removal.

Figure 8 shows the equilibrium adsorption isotherms of AO onto mesoporous carbon materials. It was observed that the adsorption rapidly increased at low concentrations of the dye and starting from its certain concentration the adsorption reaches a plateau. At low dye concentrations, the ratio of surface active sites to the total dye molecules in the solution is high, and hence all AO molecules may interact with the active functional groups on the surface of the samples obtained. Above a certain concentration, a limited number of active sites on the surface of mesoporous carbons become saturated.

The samples modified with APS show higher sorption capacities towards the basic dye AO than the pristine carbon $\mathrm{C}_{\mathrm{KIT}-6}$. Most probably this correlation is related to the chemical properties of the functionalised materials. Samples $\mathrm{C}_{\mathrm{KIT}-6}$-APS-30, $\mathrm{C}_{\mathrm{KIT}-6}$-APS-60, $\mathrm{C}_{\mathrm{KIT}-6}$-APS-100 have high content of acidic oxygen functional groups, which is essential for adsorption of cationic dye. The acidic functional groups (e.g. carboxylic, phenolic groups) enhance the interaction between the carbon materials surface and the basic dye. According to the amount of the dye adsorbed the samples can be ordered as follows: $\mathrm{C}_{\mathrm{KIT}-6}(172 \mathrm{mg} / \mathrm{g})$ $<$ C $_{\text {KIT-6- }}$-APS-30 (269 mg/g) $<$ C $_{\text {KIT-6 }}$-APS-60 (323 mg/ g) $<$ C $_{\text {KIT- } 6}$-APS-100 $(355 \mathrm{mg} / \mathrm{g})$.

A comparison of the maximum sorption capacities towards $\mathrm{AO}$ with some recent results obtained using different types of adsorbent, is presented in Table 3. The maximum amounts of the dye adsorbed on the surface of the oxidised mesoporous carbon samples of regular structure are much higher than those adsorbed on the activated carbon samples and bagasse fly ash (Mall et al. 2007). The 


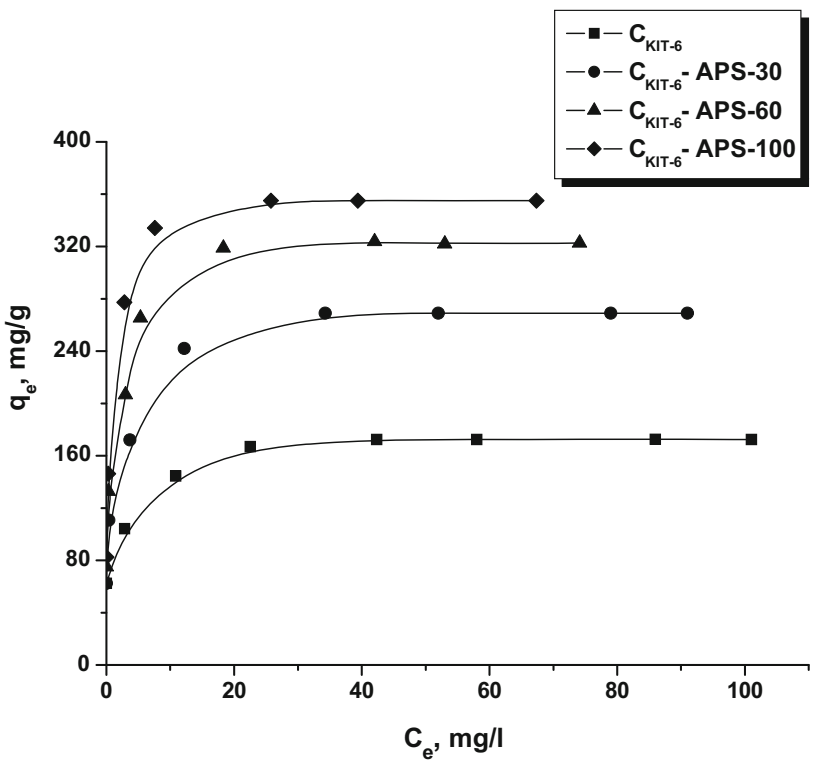

Fig. 8 Isotherms of Auramine-O adsorption onto mesoporous carbons

carbon samples $\mathrm{C}_{\mathrm{KIT}-6}$ modified with ammonium persulfate solution at 60 and $100{ }^{\circ} \mathrm{C}$ also show higher sorption capacities towards AO than the natural biopolymer $\operatorname{poly}(\gamma-$ glutamic acid) (Inbaraj et al. 2006). Only the natural untreated clay (NUC) is a more effective adsorbent of the basic dye studied than the functionalised mesoporous carbon samples synthesised (Öztürk and Malkoc 2014). To sum up, we can conclude that samples $\mathrm{C}_{\mathrm{KIT}-6}$-APS-30, $\mathrm{C}_{\mathrm{KIT}-6}$-APS-60 and $\mathrm{C}_{\mathrm{KIT}-6}$-APS-100, thanks to their specific physicochemical properties, make very efficient adsorbents of cationic dyes.

The Langmuir and Freundlich isotherm models were used to interpret and evaluate the adsorption data from the experiments (Bartczak et al. 2015; Ciesielczyk et al. 2013, 2015b; Goscianska et al. 2014, 2015a, b; Klapiszewski et al. 2015). The Langmuir adsorption isotherm is mathematically expressed as (Langmuir 1918):
$\frac{C_{e}}{q_{e}}=\frac{1}{q_{m} K_{L}}+\frac{C_{e}}{q_{m}}$

where $\mathrm{q}_{\mathrm{m}}$ is the theoretical maximum adsorption capacity $[\mathrm{mg} / \mathrm{g}], \mathrm{K}_{\mathrm{L}}$ is the Langmuir equilibrium constant $[\mathrm{mg} / \mathrm{g}]$, $\mathrm{C}_{\mathrm{e}}$ is the equilibrium concentration $[\mathrm{mg} / \mathrm{l}]$ and $\mathrm{q}_{\mathrm{e}}$ is the equilibrium adsorption amount $[\mathrm{mg} / \mathrm{g}]$. The values of $\mathrm{q}_{\mathrm{m}}$ and $\mathrm{K}_{\mathrm{L}}$ can be found from the intercept and the slope of the $\mathrm{C}_{\mathrm{e}} / \mathrm{q}_{\mathrm{e}}$ versus $\mathrm{C}_{\mathrm{e}}$ linear plot (Fig. 9a). The calculated parameters of Langmuir equation are listed in Table 4. Langmuir isotherm fits better to the experimental data than other isotherms for AO adsorption onto mesoporous carbons oxidised by ammonium persulfate. All relations between $\mathrm{C}_{\mathrm{e}} / \mathrm{q}_{\mathrm{e}}$ and $\mathrm{C}_{\mathrm{e}}$ are linear and characterised by the correlation coefficient value $\mathrm{R}^{2}$ higher than 0.999 . It should be noted that the experimental values of maximum adsorption capacities $\left(\mathrm{q}_{\mathrm{e}}\right)$ are close to the theoretical value of the maximum adsorption capacities $\left(\mathrm{q}_{\mathrm{m}}\right)$. The samples $\mathrm{C}_{\text {KIT-6}}$-APS-30, $\mathrm{C}_{\text {KIT-6}}$-APS-60, $\mathrm{C}_{\text {KIT-6}}$-APS-100 show greater adsorption affinity toward $\mathrm{AO}$ than the pristine carbon $\mathrm{C}_{\mathrm{KIT}-6}$, as indicated by $\mathrm{K}_{\mathrm{L}}$ values (Table 4 ). It can be explained by the fact that the surface carboxylic and phenolic groups can act as weak acid sites, favouring binding affinity toward the basic dye adsorbate.

The Freundlich adsorption isotherm is mathematically expressed as (Freundlich 1906):

$\ln q_{e}=\ln K_{F}+\frac{1}{n} \ln C_{e}$

where $\mathrm{K}_{\mathrm{F}}$ and $\mathrm{n}$ represent the Freundlich constants, $\mathrm{q}_{\mathrm{e}}$ is the amount of AO adsorbed at equilibrium $[\mathrm{mg} / \mathrm{g}], \mathrm{C}_{\mathrm{e}}$ is the equilibrium concentration of dye $[\mathrm{mg} / \mathrm{l}]$. The plots of $1 \mathrm{nq}_{\mathrm{e}}$ versus $\operatorname{lnC}_{\mathrm{e}}$ are presented in Fig. $9 \mathrm{~b}$. The Freundlich adsorption model assumes non-ideal adsorption by formation of a multilayer of the adsorbate on a heterogeneous surface characterised by uniform energy. The $1 / \mathrm{n}$ value below one indicates a normal Langmuir isotherm, whereas $1 / \mathrm{n}$ above one indicates cooperative adsorption. For AO adsorption on the surface of functionalised mesoporous
Table 3 Comparison of the adsorption capacity of mesoporous carbons towards Auramine-O with various adsorbents

\begin{tabular}{lcl}
\hline Adsorbent & $\mathrm{q}_{\max }(\mathrm{mg} / \mathrm{g})$ & References \\
\hline Activated carbon-commercial grade (ACC) & 1.51 & Mall et al. (2007) \\
Activated carbon-laboratory grade (ACL) & 12.55 & Mall et al. (2007) \\
Bagasse fly ash & 31.17 & Mall et al. (2007) \\
Poly $(\gamma$-glutamic acid) & 277.29 & Inbaraj et al. (2006) \\
Natural untreated clay (NUC) & 833.33 & Öztürk and Malkoc (2014) \\
Mesoporous carbon $\mathrm{C}_{\text {KIT-6 }}$ & 172.00 & This study \\
Mesoporous carbon oxidised at $30{ }^{\circ} \mathrm{C}\left(\mathrm{C}_{\text {KIT-6}}-\right.$ APS-30) & 269.14 & This study \\
Mesoporous carbon oxidised at $60^{\circ} \mathrm{C}\left(\mathrm{C}_{\text {KIT-6-APS-60) }}\right.$ & 323.21 & This study \\
Mesoporous carbon oxidised at $100{ }^{\circ} \mathrm{C}\left(\mathrm{C}_{\text {KIT-6- }}\right.$-APS-60) & 355.18 & This study \\
\hline
\end{tabular}



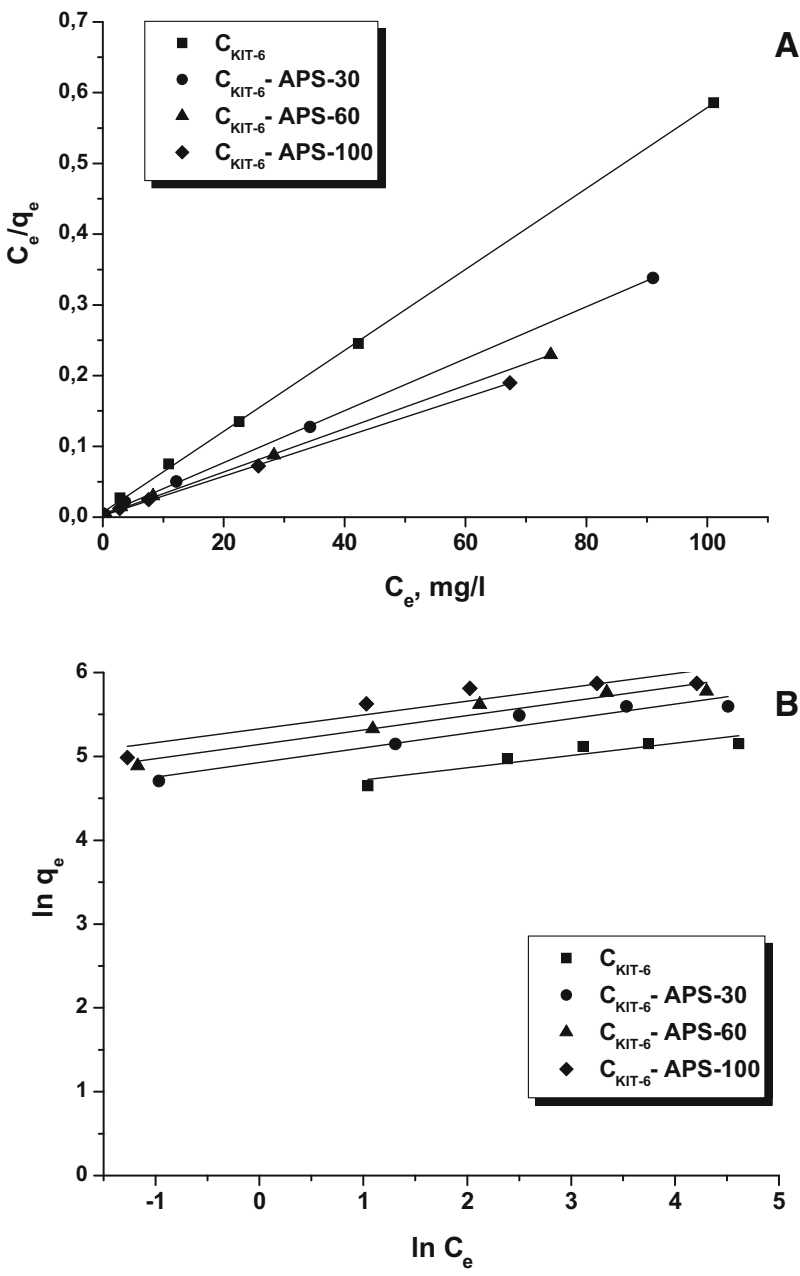

Fig. 9 Langumir (a) and Freundlich (b) isotherms of Auramine-O adsorption onto mesoporous carbons oxidised by APS

carbon samples, the values $1 / \mathrm{n}$ are similar and lower than one (Table 4).

In order to estimate the influence of temperature on the adsorption process, the thermodynamic parameters that must be considered are the changes in standard enthalpy $\left(\Delta \mathrm{H}^{0}\right)$, standard entropy $\left(\Delta \mathrm{S}^{0}\right)$ and Gibbs free energy $\left(\Delta \mathrm{G}^{0}\right)$ (Goscianska et al. 2014). The values of $\Delta \mathrm{G}^{0}, \Delta \mathrm{H}^{0}$ and $\Delta \mathrm{S}^{0}$ were computed using the following equations:
$\Delta \mathrm{G}^{0}=-\mathrm{RT} \ln \mathrm{K}_{\mathrm{d}}$

$\ln K_{d}=\frac{\Delta S^{0}}{R}-\frac{\Delta H^{0}}{R T}$

$\Delta \mathrm{G}^{0}=\Delta \mathrm{H}^{0}-\mathrm{T} \Delta \mathrm{S}^{0}$

where $\mathrm{R}(8.314 \mathrm{~J} / \mathrm{mol} \mathrm{K})$ is the universal gas constant, $\mathrm{T}$ $(\mathrm{K})$ is the absolute solution temperature, and $\mathrm{K}_{\mathrm{d}}$ is the distribution coefficient which can be defined as:

$K_{d}=\frac{C_{A e}}{C_{e}}$

where $\mathrm{C}_{\mathrm{Ae}}$ is the amount of the adsorbate adsorbed on solid $(\mathrm{mg} / \mathrm{g})$ and $\mathrm{C}_{\mathrm{e}}$ is the equilibrium concentration $(\mathrm{mg} / \mathrm{ml})$. The values of $\Delta \mathrm{H}^{0}$ and $\Delta \mathrm{S}^{0}$ were calculated from the slope and intercept of the plot of $\ln K_{d}$ versus $1 / T$. The negative free energy changes $\left(\Delta G^{0}\right)$ at all temperatures studied suggested that the adsorption of $\mathrm{AO}$ onto mesoporous carbons modified with ammonium persulfate was feasible and spontaneous thermodynamically. Moreover, an increase in the value of $\Delta \mathrm{G}^{0}$ was noted when the temperature was changed from 25 to $45^{\circ} \mathrm{C}$, indicating the decrease in spontaneity at higher temperatures. In Table 5, the negative values of $\Delta \mathrm{H}^{0}$ confirm the exothermic nature of dye adsorption. Sorption capacities of all samples towards AO decrease with increasing temperature. The negative value of $\Delta \mathrm{S}^{0}$ indicates the decrease in randomness during the adsorption process.

\section{Conclusions}

Mesoporous carbon $\mathrm{C}_{\mathrm{KIT}-6}$ obtained by the hard template method was subjected to oxidation by ammonium persulfate at 30,60 or $100{ }^{\circ} \mathrm{C}$. The process of modification of the sample was found to lead to a decrease in the surface area and pore volume, which can be explained by partial blocking of the micropores or small mesopores by the attached surface oxides. The mesoporous regular structure of $\mathrm{C}_{\mathrm{KIT}-6}$ is preserved even after oxidation at $100{ }^{\circ} \mathrm{C}$. Higher temperature of oxidation process was favourable for generation of higher density of carboxylic, phenolic and
Table 4 Summary of parameters calculated from fitting the results of adsorption isotherms of Auramine-O onto mesoporous carbons to different models

\begin{tabular}{|c|c|c|c|c|c|c|c|}
\hline \multirow[t]{2}{*}{ Material } & \multirow[t]{2}{*}{$\mathrm{q}_{\mathrm{e}(\exp )}(\mathrm{mg} / \mathrm{g})$} & \multicolumn{3}{|l|}{ Langmuir } & \multicolumn{3}{|l|}{ Freundlich } \\
\hline & & $\mathrm{q}_{\mathrm{m}}(\mathrm{mg} / \mathrm{g})$ & $\mathrm{K}_{\mathrm{L}}(\mathrm{l} / \mathrm{mg})$ & $\mathrm{R}^{2}$ & $\mathrm{~K}_{\mathrm{F}}\left[\mathrm{mg} / \mathrm{g}(1 / \mathrm{mg})^{1 / \mathrm{n}}\right]$ & $1 / \mathrm{n}$ & $\mathrm{R}^{2}$ \\
\hline $\mathrm{C}_{\mathrm{KIT}-6}$ & 172 & 175 & 0.84 & 0.999 & 96.92 & 0.15 & 0.919 \\
\hline $\mathrm{C}_{\text {KIT-6-APS-30 }}$ & 269 & 272 & 1.07 & 0.999 & 138.01 & 0.17 & 0.932 \\
\hline $\mathrm{C}_{\text {KIT-6-APS-60 }}$ & 323 & 327 & 1.26 & 0.999 & 171.27 & 0.17 & 0.928 \\
\hline $\mathrm{C}_{\text {KIT- } 6}$-APS-100 & 355 & 360 & 1.32 & 0.999 & 206.43 & 0.18 & 0.916 \\
\hline
\end{tabular}


Table 5 Thermodynamic parameters for the adsorption of Auramine-O onto mesoporous carbons

\begin{tabular}{lllll}
\hline Material & Temperature $\left({ }^{\circ} \mathrm{C}\right)$ & $\Delta \mathrm{G}^{0}(\mathrm{~kJ} / \mathrm{mol})$ & $\Delta \mathrm{H}^{0}(\mathrm{~kJ} / \mathrm{mol})$ & $\Delta \mathrm{S}^{0}(\mathrm{~J} / \mathrm{K} \mathrm{mol})$ \\
\hline $\mathrm{C}_{\text {KIT-6 }}$ & 25 & -22.61 & -28.18 & -18.97 \\
& 35 & -22.37 & & \\
$\mathrm{C}_{\text {KIT-6 }}$-APS-30 & 45 & -21.93 & & -8.46 \\
& 25 & -25.95 & -28.28 & \\
& 35 & -25.69 & & -16.79 \\
C $_{\text {KIT-6-APS-60 }}$ & 45 & -25.32 & & \\
& 25 & -27.20 & -32.06 & -53.24 \\
& 35 & -26.75 & & \\
$\mathrm{C}_{\text {KIT-6 }}$-APS-100 & 45 & -26.65 & & \\
& 25 & -26.32 & -42.33 & \\
& 35 & -26.19 & & \\
& 45 & -25.02 & & \\
\end{tabular}

etheric groups. Thanks to the presence of such groups on the surface, these materials are highly dispersible in water. Functionalised mesoporous carbons were evidenced to be a very efficient adsorbents to remove AO which is a hazardous dye. The dye adsorption equilibrium was rapidly achieved after 100 min of contact time. The adsorption of the dye increased with increasing initial AO concentration. The samples $\mathrm{C}_{\mathrm{KIT}-6}$-APS-30, $\mathrm{C}_{\mathrm{KIT}-6}$-APS-60, $\mathrm{C}_{\mathrm{KIT}-6}$-APS100 showed a higher adsorption affinity towards AO than the pristine carbon $\mathrm{C}_{\mathrm{KIT}-6}$. This observation can be explained by the fact that the surface carboxylic and phenolic groups can act as weak acid sites, favouring binding affinity towards the basic dye adsorbate. The equilibrium data were analysed by the Langmuir and Freundlich models, which revealed that Langmuir model was more suitable to describe the AO adsorption than Freundlich model. The negative values of $\Delta \mathrm{G}^{0}$ and $\Delta \mathrm{H}^{0}$ showed that the adsorption was a spontaneous and exothermic process.

Open Access This article is distributed under the terms of the Creative Commons Attribution 4.0 International License (http://crea tivecommons.org/licenses/by/4.0/), which permits unrestricted use, distribution, and reproduction in any medium, provided you give appropriate credit to the original author(s) and the source, provide a link to the Creative Commons license, and indicate if changes were made.

\section{References}

Álvarez, S., Ribeiro, R.S., Gomes, H.T., Sotelo, J.L., García, J.: Synthesis of carbon xerogels and their application in adsorption studies of caffeine and diclofenac as emerging contaminants. Chem. Eng. Res. Des. 95, 229-238 (2015)

Asfaram, A., Ghaedi, M., Hajati, S., Rezaeinejad, M., Goudarzi, A., Purkait, M.K.: Rapid removal of Auramine-O and Methylene blue by $\mathrm{ZnS}$ : $\mathrm{Cu}$ nanoparticles loaded on activated carbon: a response surface methodology approach. J. Taiwan Inst. Chem. Eng. 53, 80-91 (2015)

Barczak, M., Michalak-Zwierz, K., Gdula, K., Tyszczuk-Rotko, K., Dobrowolski, R., Dąbrowski, A.: Ordered mesoporous carbons as effective sorbents for removal of heavy metal ions. Microporous Mesoporous Mater. 211, 162-173 (2015)

Bartczak, P., Norman, M., Klapiszewski, Ł., Karwańska, N., Kawalec, M., Baczyńska, M., Wysokowski, M., Zdarta, J., Ciesielczyk, F., Jesionowski, T.: Removal of nikel(II) and lead(II) ions from aqueous solution using peat as a low-cost adsorbent: a kinetic and equilibrium study. Arab. J. Chem. (2015). doi:10.1016/j.arabjc.2015.07.018

Bazuła, P.A., Lu, A.H., Nitz, J.J., Schuth, F.: Surface and pore structure modification of ordered mesoporous carbons via a chemical oxidation approach. Microporous Mesoporous Mater. 108, 266-275 (2008)

Boehm, H.P.: Some aspects of the surface chemistry of carbon blacks and other carbons. Carbon 32, 759-769 (1994)

Ciesielczyk, F., Bartczak, P., Jesionowski, T.: A comprehensive study of $\mathrm{Cd}(\mathrm{II})$ ions removal utilizing high-surface-area binary $\mathrm{Mg}$-Si hybrid oxide adsorbent. Int. J. Environ. Sci. Technol. 12, 3613-3626 (2015a)

Ciesielczyk, F., Bartczak, P., Jesionowski, T.: Removal of nickel(II) and cadmium(II) ions from aqueous solutions using an oxide adsorbent of $\mathrm{MgO} \cdot \mathrm{SiO}_{2}$ type. Desalin. Water Treat. 55, 1271-1284 (2015b)

Ciesielczyk, F., Bartczak, P., Wieszczycka, K., Siwinska-Stefanska, K., Nowacka, M., Jesionowski, T.: Adsorption of Ni(II) from model solutions using co-precipitated inorganic oxides. Adsorption 19, 423-434 (2013)

Deng, Y.H., Cai, Y., Sun, Z.K., Gu, D., Wei, J., Li, W., Guo, X.H., Yang, J.P., Zhao, D.Y.: Controlled synthesis and functionalization of ordered large-pore mesoporous carbons. Adv. Funct. Mater. 20, 3658-3665 (2010)

Feng, J.J., Xu, J.J., Chen, H.Y.: Direct electron transfer and electrocatalysis of hemoglobin adsorbed on mesoporous carbon through layer-by-layer assembly. Biosens. Bioelectron. 22, 1618-1624 (2007)

Freundlich, H.M.F.: Over the adsorption in solution. J. Phys. Chem. 57, 385-470 (1906)

Goscianska, J., Marciniak, M., Pietrzak, R.: Mesoporous carbons modified with lanthanum(III) chloride for methyl orange adsorption. Chem. Eng. J. 247, 258-264 (2014)

Goscianska, J., Ptaszkowska, M., Pietrzak, R.: Equilibrium and kinetic studies of chromotrope $2 \mathrm{R}$ adsorption onto ordered mesoporous carbons modified with lanthanum. Chem. Eng. J. 270, 140-149 (2015a)

Goscianska, J., Marciniak, M., Pietrzak, R.: Ordered mesoporous carbons modified with cerium as effective adsorbents for azo dyes removal. Sep. Purif. Technol. 154, 236-245 (2015b) 
Hartmann, M.: Ordered mesoporous materials for bioadsorption and biocatalysis. Chem. Mater. 17, 4577-4593 (2005)

Inbaraj, B.S., Chien, J.T., Ho, G.H., Yang, J., Chen, B.H.: Equilibrium and kinetic studies on sorption of basic dyes by a natural biopolymer poly $(\gamma$-glutamic acid $)$. Biochem. Eng. J. 31, 204-215 (2006)

Jia, Y.F., Thomas, K.M.: Adsorption of cadmium ions on oxygen surface sites in activated carbon. Langmuir 16, 1114-1122 (2000)

Jun, S., Joo, S.H., Ryoo, R., Kruk, M., Jaroniec, M., Liu, Z., Ohsuna, T., Terasaki, O.: Synthesis of new, nanoporous carbon with hexagonally ordered mesostructure. J. Am. Chem. Soc. 122, 10712-10713 (2000)

Kim, T.-W., Kim, M.-J., Chae, H.-J., Ha, K.-S., Kim, C.-U.: Ordered mesoporous carbon supported uniform rhodium nanoparticles as catalysts for higher alcohol synthesis from syngas. Fuel 160, 393-403 (2015)

Klapiszewski, Ł., Bartczak, P., Wysokowski, M., Jankowska, M., Kabat, K., Jesionowski, T.: Silica conjugated with kraft lignin and its use as a novel 'green' sorbent for hazardous metal ions removal. Chem. Eng. J. 260, 684-693 (2015)

Langmuir, I.: The adsorption of gases on plane surfaces of glass, mica and platinum. J. Am. Chem. Soc. 40, 1361-1403 (1918)

Lazaro, M.J., Calvillo, L., Bordeje, E.G., Moliner, R., Juan, R., Ruiz, C.R.: Functionalization of ordered mesoporous carbons synthesized with SBA-15 silica as template. Microporous Mesoporous Mater. 103, 158-165 (2007)

Lin, M.L., Lo, M.Y., Mou, C.Y.: Pt Ru nanoparticles supported on ozone-treated mesoporous carbon thin film as highly active anode materials for direct methanol fuel cells. J. Phys. Chem. C 113, 16158-16168 (2009)

Mall, I.D., Srivastava, V.C., Agarwal, N.K.: Adsorptive removal of Auramine-O: kinetic and equilibrium study. J. Hazard. Mater. 143, 386-395 (2007)

Martelli, A., Campart, G.B., Canonero, R., Carozzino, R., Mattioli, F., Robbiano, L., Cavanna, M.: Evaluation of auramine genotoxicity in primary rat and human hepatocytes and in the intact rat. Mutat. Res. 414, 37-47 (1998)

Moreno-Tovar, R., Terrés, E., Rangel-Mendez, R.J.: Oxidation and EDX elemental mapping characterization of an ordered mesoporous carbon: $\mathrm{Pb}(\mathrm{II})$ and $\mathrm{Cd}(\mathrm{II})$ removal. Appl. Surf. Sci. 303, 373-380 (2014)

Otake, Y., Jenkins, R.G.: Characterization of oxygen-containing surface complexes created on a microporous carbon by air and nitric acid treatment. Carbon 31, 109-121 (1993)

Öztürk, A., Malkoc, E.: Adsorptive potential of cationic basic yellow 2 (BY2) dye onto natural untreated clay (NUC) from aqueous phase: mass transfer analysis, kinetic and equilibrium profile. Appl. Surf. Sci. 299, 105-115 (2014)

Ryoo, R., Joo, S.H., Jun, S.: Synthesis of highly ordered carbon molecular sieves via template-mediated structural transformation. J. Phys. Chem. B 103, 7743-7747 (1999)

Ryoo, R., Joo, S.H., Kruk, M., Jaroniec, M.: Ordered mesoporous carbon. Adv. Mater. 13, 677-681 (2001)

Tanaka, S., Fujimoto, H., Denayer, J.F.M., Miyamoto, M., Oumi, Y., Miyake, Y.: Surface modification of soft-templated ordered mesoporous carbon for electrochemical supercapacitors. Microporous Mesoporous Mater. 217, 141-149 (2015)

Tian, Y., Liu, P., Wang, X., Lin, H.: Adsorption of malachite green from aqueous solutions onto ordered mesoporous carbons. Chem. Eng. J. 171, 1263-1269 (2011)

Wu, Z., Webley, P.A., Zhao, D.: Comprehensive study of pore evolution, mesostructural stability, and simultaneous surface functionalization of ordered mesoporous carbon (FDU-15) by wet oxidation as a promising adsorbent. Langmuir 26, 10277-10286 (2010)

Zhou, M., Ding, J., Guo, L.P., Shang, Q.K.: Electrochemical behavior of L-cysteine and its detection at ordered mesoporous carbonmodifi ed glassy carbon electrode. Anal. Chem. 79, 5328-5335 (2007) 